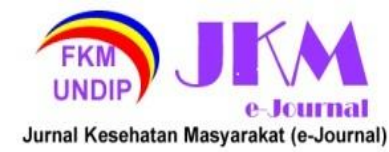

JURNAL KESEHATAN MASYARAKAT (e-Journal)

Volume 9, Nomor 6, November 2021

ISSN: 2715-5617 / e-ISSN: 2356-3346

http://ejournal3.undip.ac.id/index.php/jkm

\title{
HUBUNGAN ANTARA GERAKAN REPETITIF DAN POSTUR KERJA DENGAN KEJADIAN CARPAL TUNNEL SYNDROME PADA PEKERJA PENGUPAS KULIT KELAPA MANUAL DI PASAR TRADISIONAL SE - KOTA SURAKARTA
}

\author{
Nabilah Putri Aprilia ${ }^{1 *}$, Baju Widjasena², Suroto ${ }^{2}$ \\ ${ }^{1}$ Peminatan Keselamatan dan Kesehatan Kerja, Fakultas Kesehatan Masyarakat, Universitas \\ Diponegoro, JI. Prof. H. Soedarto, S.H.,Tembalang, Semarang, Indonesia \\ Bagian Keselamatan dan Kesehatan Kerja, Fakultas Kesehatan Masyarakat, Universitas \\ Diponegoro, Jl. Prof. H. Soedarto, S.H.,Tembalang, Semarang, Indonesia \\ *Corresponding author: nabilahpputri@gmail.com
}

\begin{abstract}
Traditional markets are one of the informal sectors that have an important role in people's lives. One of the commodities that being sold is coconut. Manual coconut shell peeler workers when working often perform repetitive movements and poses in awkward work postures, especially extreme wrist positions for long periods of time. Its a risk for the occurrence of Carpal Tunnel Syndrome in workers. This research aim to find out the corellation between repetitive movements and work postures with the incidence of CTS in Manual Coconut Shell Peeler Workers in Traditional Markets of Surakarta City. This research was quantitative with cross sectional method. Research's population was manual coconut shell peeler workers in traditional markets throughout the city of Surakarta. Samples was taken by incidental technique consisting of 30 respondents from 5 traditional markets in Surakarta. The independent variables are repetitive movements and work postures. The dependent variable is the incidence of CTS, while the confounding variables are history of diseases or acute trauma, pregnancy, and nutritional status. Data were collected using google form and analyzed using Chi Square and Spearman Rank. The results showed that the $p$-value of the repetitive movement with the incidence of CTS was $0.003<0.05$ performed by Chi-Square test, while the p-value of work posture with the incidence of CTS was $0.013<0.05$ performed by Spearman Rank. There is a corellation between repetitive movements and work postures with the incidence of CTS in manual coconut shell peelers in traditional markets throughout Surakarta City.
\end{abstract}

Keywords : CTS, manual coconut shell peeler workers, repetitive movements, traditional markets, work postures

\section{PENDAHULUAN}

Pasar tradisional termasuk ke dalam salah satu sektor informal yang memiliki peran penting dalam kehidupan masyarakat. ${ }^{(1)}$ Pasar tradisional menjual berbagai macam komoditi di dalamnya, salah satunya ialah kelapa. Bagian - bagian buah kelapa dapat diolah sehingga menjadi produk yang bernilai ekonomi, khususnya daging buah kelapa.(2) Oleh karena itu, terdapat pekerja pengupas kulit kelapa yang bertugas untuk memisahkan daging kelapa dengan kulit kelapa. Pekerja pengupas kulit kelapa terbagi menjadi dua, yaitu pekerja pengupas kulit kelapa manual dan pekerja pengupas kulit kelapa yang menggunakan alat bantu mesin.

Pekerja pengupas kulit kelapa manual dalam melakukan pekerjaan sehari- harinya seringkali melakukan gerakan repetitif dan dalam postur yang janggal, khususnya postur lengan yang ekstrem. Pekerja dalam mengupas tempurung kelapa masih menggunakan alat bantu tradisional, seperti pisau, parang, atau alat tajam lainnya. Kegiatan ini tidak hanya berisiko pada keselamatan para pekerja, namun juga pada kesehatan para pekerja. Pekerja berisiko mengalami masalah kesehatan, salah satunya ialah Penyakit Akibat Kerja (PAK). Menurut Perpres Nomor 7 tahun 2019, PAK adalah penyakit yang disebabkan oleh pekerjaan dan/atau lingkungan kerja.(3)

$$
\text { Carpal Tunnel Syndrome (CTS) }
$$

merupakan salah satu PAK yang dapat diderita oleh pekerja. Carpal Tunnel Syndrome adalah satu bentuk dari neuropati saraf perifer yang paling sering dijumpai dikarenakan penekanan saraf medianus oleh organ-organ yang terletak pada canalis carpi dengan gejala utama berupa kesemutan, dan rasa nyeri yang menjalar pada daerah distribusi saraf medianus, rasa kebas, kelemahan otot, dan dapat diikuti oleh adanya atrofi otot saraf.(4) Beberapa studi baru-baru ini kegiatan pekerjaan yang berisiko CTS antara lain kegiatan yang melibatkan gerakan repetitif, 


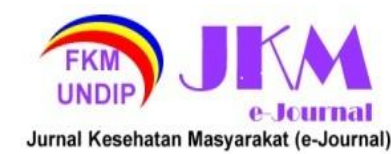

bertenaga dan berkelanjutan dari tangan dan pergelangan tangan, paparan terhadap getaran, atau kombinasi dari semua faktor itu. ${ }^{(5)}$

Postur kerja merupakan posisi relatif dari bagian tubuh tertentu para pekerja saat melakukan aktivitas pekerjaannya yang berkaitan dengan desain area kerja dan tugasnya serta ukuran dari peralatan yang digunakan dalam bekerja. ${ }^{(6)}$ Postur kerja dapat menimbulkan CTS apabila postur kerja yang statis, khususnya postur tangan tidak ergonomis saat bekerja. Bekerja dengan postur kerja yang janggal dan ekstrem dalam waktu yang lama dapat menyebabkan peradangan dan pembengkakan yang akan menekan saraf median. ${ }^{(7)}$

Gerakan repetitif adalah suatu kesatuan gerakan yang mempunyai sedikit variasi dan dilakukan tiap beberapa detik secara berulang sehingga dapat menyebabkan kelelahan dan ketegangan pada otot tendon.(8) Setiap gerakan berulang disarankan hanya dilakukan dengan jumlah frekuensi $<10$ gerakan/menit karena jika dilakukan lebih dari itu akan dikategorikan dalam tingkatan risiko gerakan dengan pengulangan yang tinggi.(9) Kegiatan yang dilakukan dengan berulang dapat menyebabkan kelelahan, kerusakan jaringan, rasa sakit dan ketidaknyamanan dalam bekerja. ${ }^{(8)}$

Menurut Biro Statistik Tenaga Kerja AS, gangguan muskuloskeletal, termasuk CTS, adalah salah satu kondisi medis paling umum di AS, yang memengaruhi $7 \%$ populasi.(10) Penelitian yang dilakukan tahun 2013 di US pada 27. 157 orang dewasa tentang prevalensi CTS dan keterkaitan kerja menyatakan bahwa prevalensi CTS di antara pekerja setinggi $6,7 \% .{ }^{(11)}$ Prevalensi penyakit CTS di Indonesia yang memiliki kaitan dengan pekerjaan belum diketahui dikarenakan pelaporan PAK di Indonesia yang masih sangat sedikit.(4)

Penelitian Carpal Tunnel Syndrome pada pekerja pengupas kulit kelapa belum pernah dilakukan sebelumnya, namun terdapat penelitian musculoskeletal disorders pada petani pengupas kulit kelapa di Kelurahan Gunung Woka Kecamatan Lembeh Utara Kota Bitung. petani pengupas kulit kelapa di Kelurahan Gunung Woka dalam mengupas kelapa dibantu oleh alat tradisional, yaitu kayu yang ditajamkan ujungnya seperti pisau serta alat pengupas kulit kelapa yang terbuat dari besi. Penelitian sikap kerja petani kelapa dengan menggunakan REBA menghasilkan 17 responden $(37,8 \%)$ memiliki sikap kerja risiko tinggi dan 28 responden $(62,2 \%)$ memiliki sikap kerja dengan risiko sedang. Mayoritas petani pengupas kulit kelapa memiliki keluhan muskuloskeletal sebanyak 16 responden 35,6\%. Hasil penelitian ini menyatakan bahwa ada hubungan antara sikap kerja dengan keluhan musculoskeletal disorders. ${ }^{(12)}$

Hasil observasi studi pendahuluan yang dilakukan pada pekerja pengupas kulit kelapa manual di salah satu pasar tradisional di kota Surakarta dalam melakukan pekerjaannya para pekerja masih sering melakukan postur kerja yang janggal. Terdapat pula gerakan repetitif fleksi dan ekstensi mengayunkan lengan yang bertenaga dilakukan oleh para pekerja. Gerakan ini dilakukan kurang lebih selama 5 jam perharinya tanpa istirahat. Hal ini berisiko menimbulkan keluhan gejala CTS pada para pekerja yang dapat mempengaruhi mereka dalam bekerja maupun dalam beraktivitas sehari- hari. Menurut pengakuan para pekerja dalam wawancara singkat yang dilakukan, keluhan yang mereka rasakan adalah rasa sakit pada telapak tangan dan pergelangan tangan. Sehingga, perlu dilakukannya penelitian mengenai hubungan gerakan repetitif dan postur kerja terhadap kejadian CTS pada pekerja pengupas kulit kelapa manual Se-Kota Surakarta.

\section{METODE PENELITIAN}

Penelitian ini menggunakan metode kuantitatif dengan pendekatan cross sectional. Populasi yang akan diteliti pada penelitian ini adalah pekerja pengupas kulit kelapa manual di pasar tradisional se - Kota Surakarta yang tidak diketahui jumlah populasinya. Sampel penelitian merupakan pekerja pengupas kulit kelapa manual berjumlah 30 responden yang didapat menggunakan rumus linear time function dengan kriteria inklusi:

a. Merupakan pekerja pengupas kulit kelapa manual;

b. Bersedia untuk menjadi responden;

c. Sedang tidak menderita sakit diabetes, hipotiroidisme, dan arthritis rheumatoid;

d. Sedang tidak hamil;

e. Tidak memiliki trauma akut;

f. IMT tidak lebih dari 27.

Kriteria inklusi dibuat untuk mengontrol variabel pengganggu agar tidak mempengaruhi hasil hubungan antara variabel bebas dan variabel terikat. Sampel pekerja pengupas kulit kelapa manual yang memenuhi kriteria inklusi merupakan pekerja pengupas 


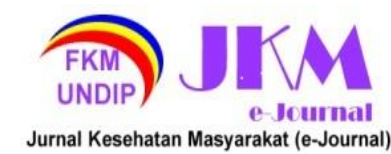

kulit kelapa manual yang berada di Pasar Legi, Pasar Nongko, Pasar Kleco, Pasar Kadipolo, dan Pasar Harjodaksino. Teknik pengambilan sampel yang digunakan ialah secara insidental, artinya teknik penentuan sampel dilakukan berdasarkan kebetulan, siapa saja yang secara kebetulan/insidental bertemu dengan peneliti dapat menjadi sampel apabila dirasa cocok sebagai sumber data untuk penelitian.

Variabel bebas dalam penelitian ini adalah gerakan repetitif dan postur kerja. Variabel terikatnya adalah kejadian Carpal Tunnel Syndrome, sedangkan variabel pengganggunya ialah riwayat penyakit atau trauma akut yang diderita, kehamilan, dan status gizi. Alat peneltitian yang digunakan dalam penelitian ini adalah google form yang berisi kuesioner modifikasi dari Boston Carpal Tunnel Syndrome Questionairre, modifikasi sheet RULA, dan phalen's test. Data yang telah dikumpulkan selanjutnya akan dianalisis menggunakan uji Chi-Square dan uji analisis korelasi Rank Spearman.

\section{HASIL DAN PEMBAHASAN}

\section{Gambaran Umum}

Kota Surakarta memiliki 44 pasar tradisional yang terdiri dari 25 pasar tradisional umum dan 19 pasar tradisional yang khusus hanya menjual 1 atau 2 komoditi barang saja. Kekinian, pasar tradisional di kota Surakarta semakin gencar dijadikan destinasi wisata oleh pemerintah Kota Surakarta. Keunikan bangunan pasar yang memiliki sejarah, keragaman jenis komoditi yang diperdagangkan, hal itu semua yang disuguhkan untuk menarik minat para pembeli. Terdapat beberapa pasar tradisional di kota
Surakarta yang dianggap paling besar dan terkenal, seperti pasar Gede, pasar Klewer, pasar Kliwon.

Pekerja pengupas kulit kelapa manual tersebar di beberapa pasar tradisional di Surakarta mengikuti fakta bahwa kelapa merupakan salah satu komoditi yang dijual pada beberapa pasar tradisional di Surakarta, baik dalam bentuk satuan maupun bulk. Beberapa pasar yang menjual komoditi di kelapa di kota Surakarta antara lain, yaitu pasar Pasar Legi, Pasar Nongko, Pasar Kleco, Pasar Kadipolo, dan Pasar Harjodaksino.

Beberapa pekerja pengupas kulit kelapa manual setiap harinya dapat mengupas \pm 500 buah kelapa per harinya seperti para pengupas kulit kelapa manual yang ada di Pasar Legi. Perbedaan jumlah ini dapat dipengaruhi oleh jumlah pesanan tiap harinya. Dengan kuantitas kelapa yang dikupas tiap harinya dan dipadu dengan postur kerja yang dilakukan pada saat bekerja, tak dipungkiri dalam jangka waktu yang lama pekerja akan dapat mulai merasakan beberapa efek samping, seperti menderita PAK, salah satunya yaitu Carpal Tunnel Syndrome.

\section{Hasil Analisis Univariat}

Setelah dilakukan penelitian kepada 30 responden pengupas kulit kelapa manual, diketahui karateristik dari para responden penelitian. Karateristik responden tersebut terdiri dari umur, jenis kelamin, status gizi (IMT), masa kerja, gerakan repetitif yang dilakukan pekerja, postur kerja pada pekerja, keluhan Carpal Tunnel Syndrome dan keluhan yang didapatkan setelah melakukan phalen's test. Karateristik responden tersebut dapat dijabarkan sebagai berikut:

Tabel 1. Karateristik Responden

\begin{tabular}{llll}
\hline Variabel & & $\mathbf{n}$ & Persentase (\%) \\
\hline Usia & $26-35$ & 7 & 23,33 \\
& $36-45$ & 9 & 30 \\
& $46-55$ & 9 & 30 \\
Jenis Kelamin & $56-65$ & 5 & 16,67 \\
Status Gizi & Laki- Laki & 15 & 50 \\
& Perempuan & 15 & 50 \\
& Sangat Kurus & 0 & 0 \\
& Kurus & 0 & 0 \\
Masa Kerja & Normal & 19 & 63,33 \\
\multirow{2}{*}{ Gerakan Repetitif } & Gemuk & 11 & 36,67 \\
& Obesitas & 0 & 0 \\
Postur Kerja & $\leq 4$ tahun & 2 & 6,67 \\
& $>4$ tahun & 28 & 93,33 \\
& $\leq 10$ gerakan/menit & 11 & 36,67 \\
& $>10$ gerakan/menit & 19 & 63,33 \\
\hline
\end{tabular}




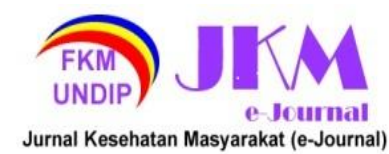

nesehatan Masyarakat (e-Journal)
JURNAL KESEHATAN MASYARAKAT (e-Journal)

Volume 9, Nomor 6, November 2021

ISSN: 2715-5617 / e-ISSN: 2356-3346

http://ejournal3.undip.ac.id/index.php/jkm

\begin{tabular}{llll}
\hline & Kecil & 8 & 26,70 \\
& Sedang & 11 & 36,70 \\
Keluhan Kejadian CTS & Tinggi & 11 & 36,70 \\
& Tidak ada gejala & 14 & 46,67 \\
& Ada gejala & 16 & 53,33 \\
\hline
\end{tabular}

Sumber: Data Primer, 2021

Berdasarkan tabel 1, diketahui faktor personal responden yang terdiri dari kehamilan, IMT (status gizi), riwayat penyakit atau trauma akut telah dikontrol oleh kriteria inklusi, sehingga variabel pengganggu dalam penelitian ini dapat dikontrol. Mayoritas responden berada di rentang usia 36 - 45 dan 46 - 55 masing - masing sebesar 9 orang. Seluruh responden berjumlah 30 masing masing 15 orang perempuan dan 15 orang laki - laki. Status gizi responden yang dilihat dari nilai IMT menunjukkan mayoritas responden memiliki status gizi normal berjumlah 19 orang. Data distribusi karateristik responden berdasarkan masa kerja responden menunjukkan mayoritas responden mempunyai pengalaman kerja selama $>4$ tahun berjumlah 28 orang dengan persentase $93,33 \%$. Mayoritas responden dalam melakukan pekerjaannya melakukan gerakan berulang dengan durasi >10 gerakan/menit berjumlah 19 orang dengan persentase $63,33 \%$. Sikap kerja responden yang diukur menggunakan kuisioner modifikasi RULA menyatakan bahwa mayoritas responden mendapatkan rentang skor 5 - 6 (risiko sedang) berjumlah 11 orang dengan persentase $36,70 \%$, dan rentang skor $\geq 7$ (risiko tinggi) berjumlah 11 orang dengan persentase $36,7 \%$. Keluhan kejadian Carpal Tunnel Syndrome responden yang didapati dengan pengisian kuesioner memperlihatkan bahwa 14 orang tidak merasakan gejala Carpal Tunnel Syndrome sedangkan 16 orang merasakan gejala Carpal Tunnel Syndrome pada diri mereka. Hasil tersebut didapati dari skor kuesioner yang didapat oleh responden serta skor phalen's test yang dilakukan.

Setelah itu, uji normalitas dilakukan pada variabel postur kerja. Hasil yang didapat dapat dijabarkan sebagai berikut:

Tabel 2. Hasil Uji Normalitas

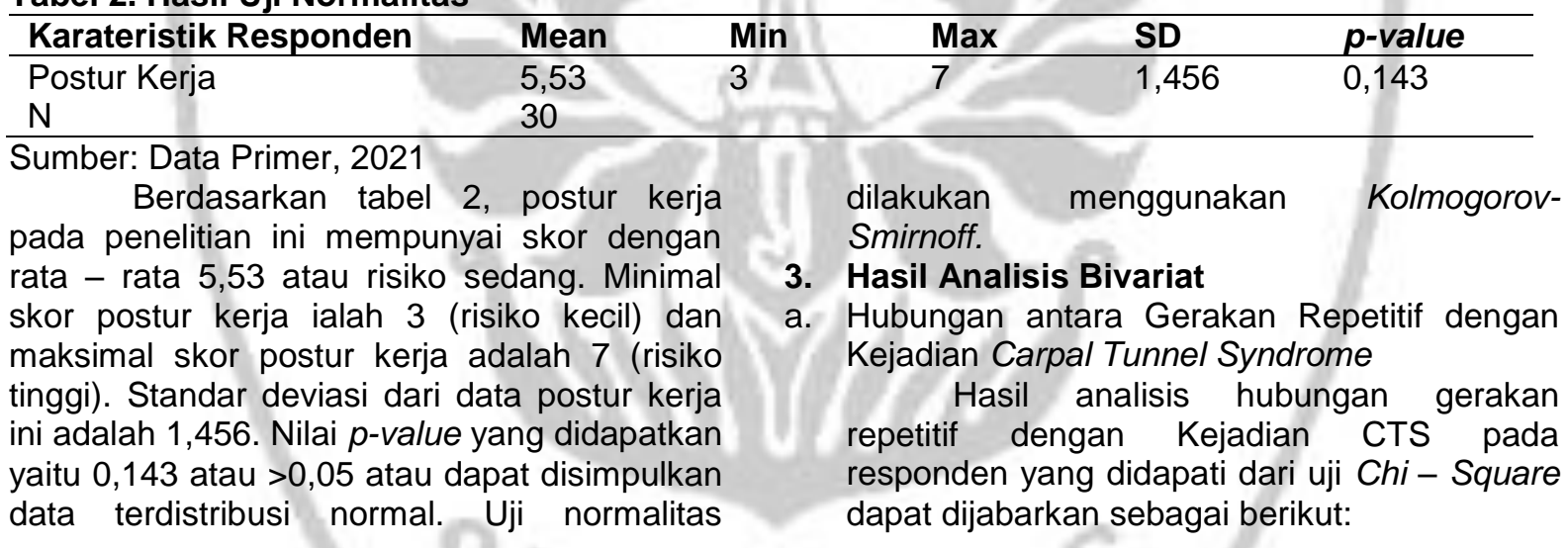

Tabel 3. Hasil Analisis Hubungan Gerakan Repetitif dengan Kejadian CTS

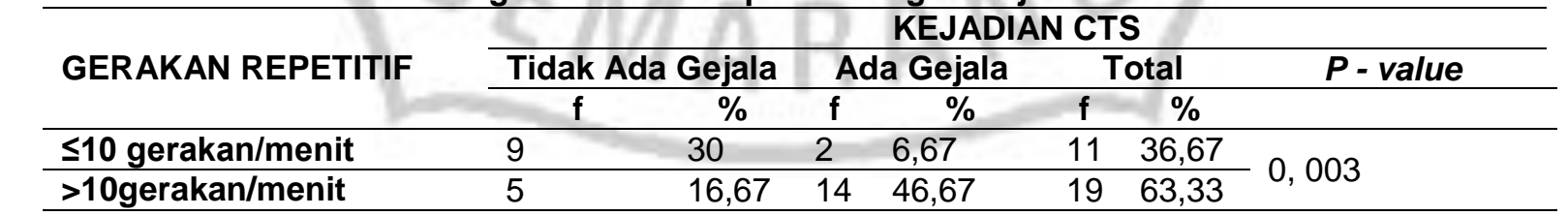

Sumber: Data Primer, 2021

Hasil analisis Chi - Square

menunjukkan nilai $p$ - value pada uji Pearson Chi - Square sebesar 0,003 , sehingga nilai $p$ $<0,05$. Karena nilai $p<0,05$, maka dapat diartikan bahwa semakin banyak frekuensi gerakan repetitif yang dilakukan dalam satu durasi waktu maka keluhan kejadian CTS yang diderita oleh pekerja akan semakin meningkat. Sebaliknya, semakin rendah frekuensi gerakan repetitif yang dilakukan dalam satu durasi waktu maka akan semakin rendah pula keluhan kejadian CTS yang diderita oleh pekerja. Hal ini dapat disimpulkan adanya hubungan antara Gerakan Repetitif 


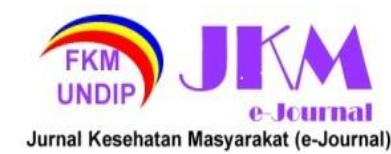

dengan Kejadian Carpal Tunnel Syndrome pada pekerja pengupas kulit kelapa manual di pasar tradisional Se - Kota Surakarta.

Gerakan berulang dan berlebihan pada tangan ini dapat meningkatkan risiko mengalami kejadian CTS pada pekerja. Hal ini dikarenakan gerakan berulang dapat menyebabkan pembengkakkan pada tendon di saraf medianus pada terowongan karpal. Pembengkakkan ini dapat mengurangi ruang yang ada pada terowongan karpal dan menjepit saraf median, sehingga dapat menyebabkan cedera pada saraf median yang akan menghasilkan gejala - gejala CTS, seperti sensasi kehilangan rasa (kebas), kesemutan, nyeri pada pergelangan tangan, atau rasa kaku pada tangan.(13) National Institute for Occupational Safety and Health (NIOSH) menyatakan pekerjaan yang saat dilakukan mengakibatkan adanya eksposur gerakan berulang pada pergelangan tangan erat kaitannya dengan adanya insidensi Carpal Tunnel Syndrome (CTS). Hal ini juga dapat disertai dengan adanya postur kerja yang janggal.(14)

Gerakan berulang yang dilakukan oleh pengupas kulit kelapa manual antara lain yaitu gerakan mengayunkan tangan secara kuat sambil memegang alat tajam untuk mengupas kulit kelapa serta fleksi dan ekstensi yang dilakukan tangan dan lengan pekerja pada saat mengambil buah kelapa yang belum dikupas dan meletakkan kembali kelapa yang sudah dikupas.

Hasil penelitian in sesuai dengan penelitian yang dilakukan oleh Fajriah Elsa Suheri pada pengupas kulit kelapa muda di wilayah Pekanbaru. Pada penelitian tersebut dapat disimpulkan bahwa postur kerja pada saat mengupas kelapa yang tidak ergonomis dan dilakukan secara berulang dapat menyebabkan berbagai keluhan otot terutama pada tubuh bagian atas. ${ }^{(15)}$

Hasil penelitian ini juga sesuai dengan penelitian Dewi Sekarsari, Arum Dian Pratiwi, dan Amrin Farzan pada tahun 2016 yang meneliti tentang hubungan lama kerja, gerakan berulang, dan postur kerja yang janggal pada tangan dengan keluhan Carpal Tunnel Syndrome pada pekerja pemecah batu di Kecamatan Moramo Utara Kabupaten Konawe Selatan. Pada penelitian tersebut disebutkan bahwa terdapat hubungan antara gerakan repetitif dengan keluhan CTS pada pekerja pemecah batu. Pernyataan itu dibuktikan dengan hasil uji statistik dengan menggunakan uji exact fischer, $\mathrm{p}$ - value 0,020 atau $p<0,05$ dengan kesimpulan terdapat hubungan antara gerakan repetitif dan keluhan CTS. ${ }^{(14)}$

b. Hubungan antara Postur Kerja dengan Kejadian CTS

Hasil dari tabulasi silang menggunakan uji analisis korelasi Rank Spearman antara variabel postur kerja dan variabel kejadian CTS mendapatkan interpretasi yang terdiri dari 3 tahap, yaitu:

1) Dari tabulasi silang tersebut, didapati angka koefisien korelasi sebesar $0,448^{*}$ yang berarti tingkat kekuatan hubungan (korelasi) antara variabel postur kerja dengan variabel keluhan CTS adalah sebesar 0,448 atau cukup kuat.

2) Dari tabulasi silang tersebut, diperoleh angka koefisien korelasi bernilai positif dengan nilai 0,448 yang artinya hubungan antara kedua variabel tersebut searah.

3) Dari tabulasi silang tersebut, diperoleh nilai signifikansi sebesar 0,013 atau 0,013 < 0,05 maka artinya ada hubungan yang signifikan antara variabel postur kerja dengan variabel keluhan CTS.

Kesimpulannya adalah terdapat hubungan signifikan yang cukup kuat dan searah antara postur kerja dengan kejadian CTS pada pekerja pengupas kulit kelapa manual. sesuai dengan hasil interpretasi uji analisis yang dilakukan, bahwa responden yang mempunyai risiko potensi cidera kerja (risiko postur kerja) yang tinggi cenderung lebih memiliki gejala kejadian CTS pada diri mereka dibandingkan responden yang melakukan postur kerja dengan risiko yang lebih kecil. Postur kerja yang janggal pada pekerja saat bekerja dapat meningkatkan skor risiko potensi cidera kerja. Skor risiko potensi cidera kerja dapat dinilai dari penilaian RULA (Rapid Upper Limb Assessment) ataupun REBA (Rapid Entire Body Assessment). Semakin tinggi risiko potensi cidera kerja maka dapat semakin meningkatkan potensi mengalami gejala CTS.

Bekerja dalam postur tubuh yang janggal membuat otot - otot tubuh bekerja dengan kurang efisien dan energi yang terpakai menjadi lebih banyak untuk menyelesaikan suatu pekerjaan. ${ }^{16)}$ Postur kerja yang statis dan janggal, khususnya postur tangan yang janggal, jika dilakukan dalam jangka waktu yang lama akan menyebabkan peradangan dan pembengkakan. (7) CTS dapat diderita oleh seseorang karena adanya peregangan dan penekanan pada syaraf median akibat berkurangnya ruang pada terowongan karpal ketika pergelangan tangan berada dalam posisi yang ekstrem. Menggunakan peralatan saat posisi pergelangan tangan ekstrem dan 


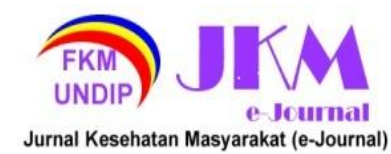

adanya tekanan juga dapat menjadi faktor penyerta yang berkontribusi dalam kejadian CTS yang ditimbulkan. ${ }^{(14)}$

Postur kerja yang dilakukan pekerja pengupas kulit kelapa manual mayoritas dilakukan dengan badan yang terlalu membungkuk, leher menunduk, gerakan fleksi dan ekstensi lengan dan pergelangan tangan secara berulang dan penuh tekanan dalam jangka waktu yang lama. Kelapa diletakkan pada alas potong dan satu tangan menahannya sedangkan tangan lain melakukan gerakan berayun denga memegang alat tajam untuk mengupas kelapa. Beberapa responden juga melakukan pekerjaannya dengan duduk pada kursi dingklik yang rendah, sehingga membuat postur tubuh dalam bekerja menjadi janggal dan mudah menimbulkan keluhan pada otot tubuh.

Postur kerja dalam bekerja yang monoton dan berulang inilah yang akan menyebabkan pembengkakan tendon pada pergelangan tangan. Kontraksi otot yang melebihi $20 \%$ akan menurunkan peredaran darah ke otot sesuai dengan tingkat kontraksi otot yang dilakukan akibat besarnya tenaga yang diperlukan. Hal ini dapat menyebabkan suplai oksigen ke otot menurun dan proses metabolisme terhambat sehingga akan terjadi penimbunan asam laktat yang menimbulkan rasa nyeri di otot. ${ }^{(17)}$

Hasil penelitian ini sesuai dengan hasil penelitian yang dilakukan oleh Eka Gloria Guit, Woodford B.S. Joseph, Chreisye K. F. Mandagi pada petani pengupas kulit kelapa di Kelurahan Gunung Woka. Pada penelitian tersebut menguji hubungan antara ukuran tubuh dan sikap kerja dengan keluhan musculoskeletal pada petani pengupas kulit kelapa. Uji Spearman yang dilakukan untuk menganalisis hubungan sikap kerja dan keluhan MSDs didapati nilai korelasi 0,388 yang artinya hubungan kedua variabel tersebut searah dan dalam kategori korelasi yang lemah. Nilai $p$ yang didapati ialah $0,008<0,05$ menunjukkan adanya hubungan antara sikap kerja dengan keluhan muskuloskeletal pada petani pengupas kulit kelapa. ${ }^{(12)}$

Hasil penelitian ini juga sesuai dengan penelitian yang dilakukan oleh Ahmad lqbal Lazuardi pada tahun 2016 kepada pekerja pemecah batu di Kecamatan Sumbersari dan Sukowono Kabupaten Jember bahwa ada hubungan yang signifikan antara postur kerja dengan gejala CTS. Hal ini dibuktikan dengan nilai signifikansi sebesar $0,000<0,05$ dan sebagian besar responden yang diteliti mengalami gejala CTS mempunyai postur kerja dengan skor RULA (skor potensi cidera kerja) yang tinggi yaitu 31 orang dari 42 responden atau $91,2 \%$. Skor RULA yang tinggi ini mengindikasi bahwa postur kerja yang selama ini dilakukan oleh para pekerja janggal dan bukan merupakan postur kerja yang benar. Hal ini menyebabkan risiko untuk mengalami PAK, khususnya CTS pada pekerja pemecah batu meningkat, sehingga diperlukan perbaikan segera pada postur kerja yang dilakukan oleh para pekerja tersebut. ${ }^{(18)}$

\section{KETERBATASAN PENELITIAN}

1. Keadaan pandemi yang menyebabkan tidak dapat dilakukannya observasi secara langsung ke tempat penelitian, sehingga tidak dapat melihat secara langsung keluhan dan keadaan para pekerja pengupas kulit kelapa manual.

2. Tidak dapat menilai postur kerja dan mengukur gerakan repetitif secara langsung dikarenakan keadaan pandemi sehingga peneliti tidak dapat secara langsung menilai postur kerja yang dilakukan oleh para responden.

3. Phalen's test dilakukan tanpa ada alat penunjang diagnose serta tidak ada peneliti untuk melihat dan mengarahkan secara langsung.

4. Ketelitian serta kejujuran dari para responden dalam mengisi google form. Oleh karena itu, tidak menutup kemungkinan adanya jawaban - jawaban oleh para responden yang tidak mewakili keadaan di lapangan sebenarnya yang dapat mempengaruhi hasil dari penelitian.

\section{KESIMPULAN}

1. Mayoritas responden melakukan postur kerja dengan risiko sedang atau risiko tinggi, dengan masing - masing risiko dilakukan oleh 11 orang atau $36,7 \%$ dari responden yang diteliti. Postur kerja yang dilakukan oleh responden ini perlu adanya perbaikan dengan segera agar menjadi postur kerja yang baik.

2. Mayoritas responden melakukan gerakan repetitif $>10$ gerakan/menit yaitu sebesar 19 orang atau $63,33 \%$ dari responden yang ada. Gerakan tersebut merupakan gerakan mengayunkan lengan untuk mengupas kulit kelapa dan gerakan mengambil dan menaruh kembali buah kelapa.

3. Faktor personal yang dapat mempengaruhi terjadinya Carpal Tunnel Syndrome (CTS) pada pekerja antara lain yaitu kehamilan, IMT, riwayat penyakit atau trauma akut yang 


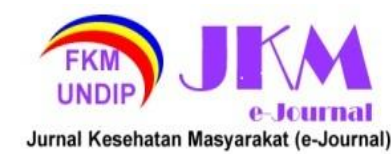

diderita. Dalam penelitian ini, seluruh faktor personal tersebut telah dikontrol dengan membuat kriteria inklusi untuk responden yang akan diteliti sehingga tidak mengganggu hubungan kedua variabel yang akan diteliti.

4. Mayoritas responden mengalami gejala Carpal Tunnel Syndrome yaitu sebanyak 16 responden atau $53,33 \%$ dari responden yang ada. Gejala CTS ditegakkan berdasarkan skor kuesioner dan skor phalen's test para responden.

5. Terdapat hubungan antara gerakan repetitif dengan Kejadian Carpal Tunnel Syndrome pada pekerja pengupas kulit kelapa manual di pasar tradisional se - kota Surakarta.

6. Terdapat hubungan signifikan yang cukup kuat dan searah antara postur kerja dengan kejadian Carpal Tunnel Syndrome pada pekerja pengupas kulit kelapa manual di pasar tradisional se - kota Surakarta.

\section{SARAN}

1. Bagi Pemerintah Setempat

Pemerintah setempat diharapkan untuk lebih peduli kepada para pekerja khususnya di tempat non formal seperti pasar tradisional dalam upaya pencegahan CTS pada pekerja non formal. Hal ini dapat dilakukan dengan penyuluhan untuk meningkatkan pengetahuan dan pemahaman pekerja tentang CTS dan upaya pencegahannya atau dengan memantau tempat kerja mereka di pasar agar setidaknya layak dan mereka dapat bekerja di tempat kerja mereka dengan postur kerja yang baik.

2. Bagi Pekerja

a. Pekerja diharapkan agar selalu senantiasa melakukan peregangan di antara waktu kerja untuk mengurangi tekanan berlebih pada syaraf median di terowongan karpal.

b. Pekerja diharapkan untuk memberikan waktu istirahat yang menjeda di sela - sela saat bekerja, agar mengurangi risiko pembengkakkan pada tendon di saraf medianus pada terowongan karpal yang dapat mengakibatkan keluhan gejala CTS dalam jangka waktu yang lama.

c. Pekerja diharapkan bekerja dengan menggunakan postur kerja yang baik atau meodifikasi tempat kerja agar dapat melakukan postur kerja yang baik terutama dalam pergerakan menggunakan pergelangan tangan agar tidak ada gerakan pergelangan tangan yang terlampau ekstrem sehingga meningkatkan risiko mengalami gejala CTS jika dilakukan dalam jangka waktu yang lama.

3. Bagi Peneliti lainnya a. Peneliti selanjutnya yang melakukan penelitian dengan tema serupa diharapkan dapat melakukan penelitian lanjutan dengan menambahkan variabel - variabel lain yang sekiranya berhubungan dan belum diteliti pada penelitian ini atau menggali faktor - faktor penyebab lainnya yang dapat menyebabkan kejadian CTS pada pekerja dan menelitinya.

b. Peneliti selanjutnya diharapkan dapat melakukan observasi secara langsung agar data yang didapatkan lebih beragam dan mendalam kepada kasus yang dialami oleh para pekerja langsung di tempat kerja mereka.

\section{DAFTAR PUSTAKA}

1. Hananto I. Hubungan Tingkat Risiko Postur Kerja Dengan Tingkat Risiko Musculosskeletal Disorder Pada Pekerja Kuli Panggul Di Pasar Legi Surakarta [skripsi]. Surakarta: Fakultas IImu Kesehatan Universitas Muhammadiyah; 2019.

2. Andriani DP, Sugiono S. Penjadwalan Waktu Istirahat Optimal untuk Mengurangi Risiko Musculoskeletal Disorders Berdasarkan OCRA Index. Jurnal IImiah Teknik Industri. 2017;15(2):157-67.

3. Indonesia. Peraturan Presiden Republik Indonesia tentang Penyakit Akibat Kerja. PP No. 7 Tahun 2019

4. Yunus M, Hasbie NF, Tami GR. Hubungan Masa Kerja dan Sikap Kerja Dengan Kejadian Carpal Tunnel Syndrome pada Pekerja Pembuat Kerupuk di Industri Pembuat Kerupuk Ahak Kecamatan Sungailiat Provinsi Bangka Belitung Tahun 2016. Jurnal IImu Kedokteran dan Kesehatan. 2016;3(3).

5. Franklin GM, Friedman AS. Work-Related Carpal Tunnel Syndrome: Diagnosis and Treatment Guideline. Physical medicine and rehabilitation clinics of North America. 2015; 26(3):523-37

6. Rinandha, Cherlly Pritta. Hubungan Postur Kerja Duduk terhadap Upper Extremity Symptoms pada Pekerja Bagian Cucuk di $P T$. Iskandartex Surakarta [skripsi]. Surakarta: Fakultas Kedokteran Universitas Sebelas Maret Surakarta; 2011.

7. Mallapiang F, Wahyudi AA. Gambaran Faktor Pekerjaan dengan Kejadian Carpal Tunnel Syndrome (CTS) pada Pengrajin Batu Tatakan di Desa Lempang Kec. Tanete Riaja Kabupaten Barru Tahun 2015. Al-sihah: The Public Health Science Journal. 2014;7(1).

8. Rina TI. Hubungan Repetitive Motion dengan Keluhan Carpal Tunnel Syndrome 


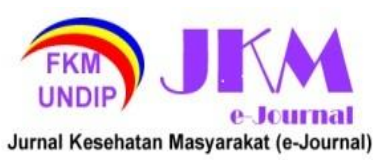

JURNAL KESEHATAN MASYARAKAT (e-Journal)

Volume 9, Nomor 6, November 2021

ISSN: 2715-5617 / e-ISSN: 2356-3346

http://ejournal3.undip.ac.id/index.php/jkm pada Pekerjaan Menjahit di Bagian Konveksi I Pt. Dan Liris Sukoharjo [skripsi]. Surakarta: Fakultas Kedokteran Universitas Sebelas Maret Surakarta; 2010.

9. Maylarini, Indah. Hubungan Gerakan Berulang dan Gerakan Fleksi Dengan Carpal Tunnel Syndrome pada Pekerja Pengguntingan Rokok Perusahaan Gama Karanganyar [skripsi]. Surakarta: Fakultas Kedokteran Universitas Sebelas Maret Surakarta; 2018.

10.U.S. Bureau of Labor Statistics. RSI Statistics [Internet]. Rsi-therapy [cited 27 July 2020] Available from: http://www.rsitherapy.com/statistics.htm

11. Luckhaupt SE, Dahlhamer JM, Ward BW, Sweeney MH, Sestito JP, Calvert GM. Prevalence and Work-Relatedness of Carpal Tunnel Syndrome in The Working Population, United States, 2010 National Health Interview Survey. American journal of industrial medicine. 2013; 566:615-24.

12.Guit EG, Joseph WB, Mandagi CK. Hubungan Antara Ukuran Tubuh dan Sikap Kerja dengan Keluhan Muskuloskeletal pada Petani Pengupas Kelapa di Kelurahan Gunung Woka Kecamatan Lembeh Utara Kota Bitung. KESMAS. 2020;9(7).

13.Retnosari, Dewi. Hubungan Gerakan Berulang dengan Keluhan Carpal Tunnel Syndrome pada Pekerja Bagian
Pelintingan PT. Rokok Gama, Karanganyar [skripsi]. Surakarta: Fakultas Kedokteran Universitas Sebelas Maret Surakarta; 2019.

14. Sari DS, Pratiwi AD, Farzan A. Hubungan Lama Kerja, Gerakan Repetitif dan Postur Janggal pada Tangan dengan Keluhan Carpal Tunnel Syndrome (CTS) pada Pekerja Pemecah Batu di Kecamatan Moramo Utara Kabupaten Konawe Selatan Tahun 2016. (Jurnal IImiah Mahasiswa Kesehatan Masyarakat). 2017 Apr 30;26.

15.Suheri FE. Rancang Ulang Alat Bantu Pengupas Kelapa Muda berdasarkan Metode Job Strain Index [skripsi]. Riau: Fakultas Sains dan Teknologi Universitas Islam Negeri Sultan Syarif Kasim Riau; 2020.

16.Kurnianto RY. Mulyono. Gambaran Postur Kerja dan Resiko Terjadinya Muskuloskeletal pada Pekerja Bagian Welding di Area Workshop Bay 4.2 PT. Alstom Power Energy Systems Indonesia. The Indonesian Journal of Occupational Safety, Health and Environment. 2014; 6172.

17.Tarwaka S, Sudiajeng L. Ergonomi untuk keselamatan, kesehatan kerja dan produktivitas. Uniba, Surakarta. 2004:3450.

18.Lazuardi, Al. Determinan Gejala Carpal Tunnel Syndrome (CTS) pada Pekerja Pemecah Batu. UNEJ PRESS; 2016. 